\title{
O ENFRENTAMENTO DA VIOLÊNCIA CONTRA AS MULHERES NO ÂMBITO DA ESTRATÉGIA DE SAÚDE DA FAMÍLIA
}

\author{
FACING VIOLENCE AGAINST WOMEN IN THE FRAMEWORK OF THE FAMILY HEALTH STRATEGY \\ EL ENFRENTAMIENTO DE LA VIOLENCIA CONTRA LAS MUJERES EN EL ÁMBITO DE LA \\ ESTRATEGIA DE SALUD DE LA FAMILIA
}

\author{
Emerson Piantino Dias* \\ Maria Ignez Costa Moreira ${ }^{*}$
}

\begin{abstract}
RESUMO
Este artigo teve como objetivo identificar ações de enfrentamento da violência contra as mulheres pela Estratégia de Saúde da Família (ESF). Foi realizada uma revisão integrativa dos artigos publicados entre 2011 e 2016, encontrados nas seguintes bases: Literatura Latino-Americana e do Caribe em Ciências da Saúde (Lilacs), Base de Dados em Enfermagem (Bdenf), Index Psicologia - Periódicos técnico-científicos e Rede Pan-Americana de Informação e Documentação em Engenharia Sanitária e Ciências do Ambiente (Repidisca). Foram encontrados 29 artigos, dos quais 13 foram selecionados para análise segundo as categorias: "o trabalho em rede com mulheres em situação de violência" e "limites e necessidades profissionais para o enfrentamento da violência de gênero". A revisão mostra lacunas na formação dos profissionais de saúde para o diagnóstico e intervenção nos casos de violência de gênero, e desarticulação entre a rede de proteção social e das equipes de saúde da família no atendimento das mulheres vítimas de violência.
\end{abstract}

Palavras-chave: Estratégia Saúde da Família. Gênero e saúde. Violência contra a mulher.

\begin{abstract}
This article aimed to identify actions in the Family Health Strategies (FHS) to face violence against women. An integrative review of articles published between 2011 and 2016 was carried out in the following databases: Latin American and Caribbean Literature in Health Sciences (Lilacs), Nursing Database (Bdenf), Index Psychology - Technical-Scientific Periodicals and Network Pan American Institute of Information and Documentation in
\end{abstract}

\footnotetext{
Texto recebido em 17 de outubro de 2018 e aprovado para publicação em 20 de dezembro de 2019.

*Doutorando em Psicologia pela Pontifícia Universidade Católica de Minas Gerais (PUC Minas), docente da Universidade Federal de Uberlândia (UFU), bolsista CAPES.E-mail: emersonpiantino@ufu.br.

" $\mathrm{PhD}$ em Psicologia Social, professora adjunta III no Programa de Pós-Graduação em Psicologia da PUC Minas. E-mail: maigcomo@uol.com.br.

Endereço: Avenida Itaú, 525 - Bairro Dom Cabral, Belo Horizonte-MG, Brasil. CEP: 30535-012.
} 
Sanitary Engineering and Environmental Sciences (Repidisca). Thirteen (13) out of the twenty-nine (29) articles we studied were selected for analysis according to the categories: "network with women in situation of violence" and "limits and professional needs to face gender violence". The review shows failures in the training of health professionals for the diagnosis and intervention in cases of gender violence, and lack of connection between the social protection network and the family health teams in the care of women victims of violence.

Keywords: Family health strategy. Gender and health. Violence against women.

\section{RESUMEN}

Este artículo objetivó identificar acciones de enfrentamiento de la violencia contra las mujeres por las Estrategias de Salud de la Familia (ESF). Se realizó una revisión integrativa de los artículos publicados entre 2011 y 2016, encontrados en las siguientes bases: Literatura Latinoamericana y del Caribe en Ciencias de la Salud (Lilacs), Base de datos en Enfermería (Bdenf), Index Psicología - Periódicos técnico-científicos y Red Panamericana de Información y Documentación en Ingeniería Sanitaria y Ciencias del Ambiente (Repidisca). Se encontraron 29 artículos, de los cuales 13 fueron seleccionados para análisis según las categorías: "el trabajo en red con mujeres en situación de violencia" y "límites y necesidades profesionales para el enfrentamiento de la violencia de género". La revisión muestra lagunas en la formación de los profesionales de la salud para el diagnóstico e intervención en los casos de violencia de género, y desarticulación entre la red de protección social y de los equipos de salud de la familia en la atención a las mujeres víctimas de violencia.

Palabras clave: Estrategia de salud familiar. Género y salud. Violencia contra la mujer.

\section{INTRODUÇÃO}

saúde da mulher é concebida como uma das áreas estratégicas da atenção
básica $(\mathrm{AB})$ no Brasil, considerada a porta de entrada preferencial do Sistema
Único de Saúde (SUS) e fortalecida pelo Programa Saúde da Família (PSF), o qual foi criado em 1994 e inspirado na experiência bem-sucedida do Programa de Agentes Comunitários de Saúde (PACS), em atuação desde 1991. Posteriormente, em sua etapa de consolidação, o PSF passou a ser denominado de Estratégia Saúde da Família (ESF). 
A ESF visa à reorganização da atenção primária de acordo com os preceitos do SUS, e é tida pelo Ministério da Saúde (MS) e gestores estaduais e municipais como estratégia de expansão, qualificação e consolidação da atenção primária, por favorecer uma orientação do processo de trabalho com maior potencial de aprofundar os princípios, diretrizes e fundamentos da atenção primária, de ampliar a resolutividade e impacto na situação de saúde das pessoas e coletividades.

Por tanto, a ESF representa uma trajetória exemplar de um programa que nasceu e se tornou uma estratégia estruturante de uma Política Nacional de Atenção Básica (PNAB), e que tem contribuído significativamente para a consolidação do SUS. Nesse sentido, o Brasil tem três importantes características em seu modelo de atenção básica da saúde: a distribuição das equipes multidisciplinares pelos territórios geográficos; a presença dos agentes comunitários de saúde; e a inclusão da saúde bucal. No contexto atual, o sistema de saúde pública brasileiro deve responder por três importantes questões: as doenças infecciosas e parasitárias, o aumento das condições crônicas e seus fatores de risco, a violência.

Neste estudo, procuramos destacar a violência intrafamiliar e doméstica como um importante agravo da saúde das mulheres, cujo enfrentamento envolve a ESF como porta de entrada na atenção primária de saúde. Destacamos que as assimetrias das relações de gênero produzem violência intrafamiliar e doméstica, fazendo das mulheres e das crianças alvos sistemáticos.

\section{A VIOLÊNCIA CONTRA AS MULHERES NA PERSPECTIVA DA CATEGORIA DE GÊNERO}

A violência de gênero representa uma grave violação dos direitos humanos que afeta a integridade psicológica e física, que prejudica a saúde das mulheres e das crianças, e constitui-se em uma prática que ameaça a vida, e, não raras vezes, é causa de óbito das mulheres. Nesse sentido, é compreendida como um problema de saúde pública.

O termo "violência" é definido pela Pan American Health Organization (PAHO) (2013) como o uso intencional da força física ou do poder, real ou em ameaça, contra si próprio, contra outra pessoa, ou contra um grupo ou uma comunidade, que resulte ou tenha grande possibilidade de resultar em lesão, morte, dano psicológico, deficiência de desenvolvimento ou privação.

O conceito de violência contra as mulheres, adotado pela Política Nacional de Enfrentamento e Combate à Violência contra as Mulheres (Ministério da Saúde, 2011), fundamenta-se na definição da Convenção de Belém do Pará (1994), segundo a qual a violência contra as mulheres constitui qualquer ação 
ou conduta, baseada no gênero, que cause morte, dano ou sofrimento físico, sexual ou psicológico à mulher, tanto no âmbito público como no privado. $\mathrm{O}$ termo "violência contra as mulheres" é usado no plural para dar visibilidade às diversidades raciais, étnicas, geracionais, de orientação sexual, de deficiência e de inserção social, econômica e regional existentes entre as mulheres.

O relatório intitulado Violência contra as mulheres na América Latina e no Caribe: uma análise comparativa dos dados sobre a população de 12 paises foi elaborado, a partir da análise da situação da violência praticada contra as mulheres na Bolívia, Colômbia, Haiti, Honduras, Peru, República Dominicana, Equador, El Salvador, Guatemala, Jamaica, Nicarágua e Paraguai, e publicado pela Organização Pan-Americana da Saúde (OPAS), em conjunto com o Centro de Controle e Prevenção e Doença dos Estados Unidos (CDC) (Pan American Health Organization, 2013).

Esse relatório mostrou que, nos 12 países da América Latina e do Caribe estudados, entre $17 \%$ e $53 \%$ das mulheres entrevistadas afirmaram ter sofrido algum tipo de violência praticada por seus parceiros. Em uma análise comparativa, evidenciou-se que, entre $10 \%$ e $27 \%$ das mulheres nesses países relataram ter sofrido violência sexual em algum momento de suas vidas, cometido por um parceiro ou por outro homem que já conheciam (Pan American Health Organization, 2013).

O tema da violência doméstica e familiar é acompanhado pelo DataSenado no Brasil (2015), em série histórica desde 2005. No ano de 2015, foram ouvidas 1.102 brasileiras e constatou-se que quase $100 \%$ das entrevistadas conheciam a Lei Maria da Penha (Lei 11.340, 2006) e também que houve um crescimento significativo na percepção de desrespeito às mulheres e nos registros de violência psicológica.

A Lei Maria da Penha completou 12 anos em 2018 e representa um marco para a proteção dos direitos das mulheres e um avanço no arcabouço legal para o enfrentamento e combate à violência. Dados oficiais estimam que, até agosto de 2018, houve aproximadamente 73 mil denúncias registradas na Central de Atendimento à Mulher em Situação de Violência, o Ligue 180 (Brito, 2018).

Os dados coletados em diversas pesquisas mostram que a primeira agressão tende a acontecer na juventude e entre mulheres com menor grau de instrução. Maridos, companheiros, namorados e ex-maridos, ex-companheiros e exnamorados continuam sendo apontados como os principais agressores. Aproximadamente $1 \mathrm{em}$ cada 5 brasileiras já sofreu algum tipo de violência doméstica ou familiar. 
Embora os dados recolhidos nos registros dos equipamentos públicos de atendimento à mulher em condição de violência apresentem características comuns entre as mulheres que buscam amparo nos serviços públicos, não há um perfil único de mulheres em situação de violência. A recorrência desses traços pode ser atribuída ao pertencimento de classe social dessas mulheres, pois a sociedade brasileira é marcada por graves desigualdades socioeconômicas, e as mulheres que acionam prevalentemente os serviços públicos têm, em sua maioria, origem nas classes populares. As mulheres de classe média e média alta, com maiores recursos financeiros e nível de escolaridade, que sofrem violência doméstica e intrafamiliar nem sempre recorrem aos equipamentos públicos e, muitas vezes, buscam atendimento de advogados e profissionais de saúde particulares. Nesse sentido, a falsa impressão de que a violência doméstica contra as mulheres atinge somente as de classes populares está associada ao fato de que essas utilizam prevalentemente os equipamentos públicos, cujas práticas são normatizadas, entre elas a exigência da notificação compulsória, e esses registros são compilados para banco de dados de acesso público.

As mulheres são recorrentemente as principais vítimas da violência, e o uso do substantivo no plural reforça que não há um perfil único de mulher que sofre violência. Nesse sentido, Saffioti e Almeida (1995) esclareceram, na apresentação do livro Violência de gênero: poder e impotência, que não há um perfil de mulher vítima de violência de gênero, pois, em seus estudos de âmbito nacional, encontraram evidências de que há uma "transversalidade da violência de gênero, que ignora fronteiras entre as classes sociais, entre países desenvolvidos e subdesenvolvidos, entre continentes étnico-raciais distintos, entre a cultura ocidental e a cultura oriental, etc.", e continuam as autoras, que "esse é um fenômeno democraticamente distribuído".

Brito (2015) encontrou, em sua pesquisa realizada entre 2013 e 2014, em um equipamento público de assistência social que atende mulheres em condições de violência, em Belo Horizonte, dados que confirmam os achados de pesquisadoras e pesquisadores que vêm se dedicando a essa temática desde a década de 1980, ou seja, a permanência da pluralidade de mulheres que sofrem violência doméstica e intrafamiliar. Os registros do equipamento público pesquisado por Brito (2015) confirmam as diferenças entre as mulheres que sofrem violência quando à faixa etária, ao grau de escolaridade, à faixa de renda e ocupação profissional, de raçaetnia e de sexualidade. Quanto à faixa etária, vale ressaltar que Brito (2015) encontrou relatos de violência sofrida por mulheres jovens agredidas pelos namorados.

Outro aspecto importante nos estudos sobre a violência doméstica e intrafamiliar, a exemplo daqueles realizados por Azevedo e Guerra (2007), Sousa 
e Moreira (2012), e Moreira e Sousa (2013), é a prática da violência doméstica e intrafamiliar contra crianças e adolescentes. A violência física e psicológica praticada contra as crianças e adolescentes é, muitas vezes, justificada pelos pais ou responsáveis como açôes educativas ou corretivas de comportamentos indesejados. A violência física é frequentemente executada pelas mães. Essa prática, lida na perspectiva da categoria de gênero, pode ser compreendida como uma reprodução da violência sofrida pelas mulheres, o que foi nomeado como síndrome do pequeno poder (Azevedo \& Guerra, 2007).

A categoria de gênero tem permitido analisar e compreender que a violência praticada contra as mulheres é produzida nas relaçôes assimétricas e desiguais de poder, que estabelecem um polo de dominação e um polo de submissão. Scott (1995) apresenta uma definição de gênero que se tornou clássica, como "um elemento constitutivo das relaçôes sociais baseado nas diferenças percebidas entre os sexos; e o gênero é uma forma primeira de significar as relações de poder" (p. 86).

Nesse sentido, a violência não é um fenômeno natural, que pode ser associado ao funcionamento hormonal de homens e mulheres ou às diferenças anatomofisiológicas de cada um deles. A violência de gênero praticada contra as mulheres é derivada dos modos de socialização vividos por homens e mulheres. Os processos de socialização, no entanto, não são estanques, mas processos contínuos e não lineares vividos em contextos históricos e socioculturais. Portanto a promoção da equidade de gênero nas relações familiares, escolares, laborais e sociais em sentido amplo é um elemento fundamental para a superação da violência contra as mulheres.

O enfrentamento da violência doméstica e intrafamiliar tem sido realizado por um conjunto de equipamentos públicos, tais como policiais, de Justiça, de Assistência Social e de Saúde. Todos esses equipamentos têm como desafio cotidiano a conexão em rede. As mulheres podem buscar ajuda em qualquer um desses pontos da rede. A ESF tem sido uma porta privilegiada, pois as mulheres tendem a estabelecer uma relação de proximidade como os profissionais da ESF, e os vínculos criados entre a equipe de saúde e as mulheres têm facilitado a constatação da violência. 


\section{A ESF E A ACOLHIDA DAS MULHERES EM SITUAÇÃO DE VIOLÊNCIA}

Os serviços de saúde, em especial no âmbito da ESF, têm recebido uma significativa demanda de atendimento das mulheres, o que torna os profissionais da saúde potenciais reconhecedores da violência contra as mulheres. Nesse sentido, o setor saúde tem papel de destaque no processo de enfrentamento dessa violência (Gomes, Bonfim, Barros, Silva Filho, \& Diniz, 2014).

No campo da saúde, a violência transforma-se em problema, no momento em que afeta a saúde individual e coletiva, o que demanda a criação de políticas públicas específicas, além da organização de serviços direcionados à prevenção e ao tratamento. É nesse contexto que o trabalho das equipes de Saúde da Família configura-se elemento-chave na identificação de casos de violência, na criação de vínculo com mulheres vítimas desses eventos, na estruturação de estratégias de enfrentamento e de ações de prevenção e promoção (Hesler, Resta, \& Colomé, 2013, p. 181).

Devido à complexidade desse fenômeno, é necessária a articulação da rede de atenção em saúde, tanto com os equipamentos de proteção social quanto com o aparato jurídico-policial. Além disso, a articulação desses múltiplos serviços exige a formação dos diversos profissionais para o exercício de práticas interdisciplinares.

Diante da importância dos profissionais da saúde e considerando a necessidade de estudos sobre o tema proposto, este estudo teve como objetivo identificar e caracterizar o conhecimento produzido no campo da saúde sobre a violência contra as mulheres e as práticas de seu enfretamento pela ESF.

\section{REVISÃO INTEGRATIVA (RI)}

Revisão integrativa (RI) é um método que busca reunir a produção científica relevante acerca de um determinado tema, oferecendo acesso rápido e sintetizado aos resultados científicos de maior importância para a área estudada. A RI compreende seis etapas:

a) identificação do problema (elaboração da pergunta norteadora, escolha dos descritores e dos critérios para inclusão/exclusão de artigos);

b) busca dos artigos na literatura;

c) categorização dos estudos; 
d) avaliação da amostra;

e) síntese dos artigos analisados;

f) interpretação dos resultados (Ganong, 1987; Mendes, Silveira, \& Galvão, 2008; Pompeo, Rossi, \& Galvão, 2009).

Para a realização da revisão, foi feito um levantamento bibliográfico na Biblioteca Virtual de Saúde (BVS), utilizando os seguintes descritores em Ciências da Saúde (DeCS): "Estratégia Saúde da Família"; "gênero e saúde”; "violência contra a mulher", como apresentado no quadro 1.

\section{Quadro 1 - Descritores utilizados no estudo}

\begin{tabular}{|c|c|}
\hline Descritores BVS utilizados & "Estratégia Saúde da Família" AND “Gênero e Saúde" AND \\
"Violência Contra a Mulher"
\end{tabular}

Fonte: Centro Latino-Americano e do Caribe de Informação em Ciências da Saúde, Organização Pan-Americana de Saúde, Organização Mundial de Saúde (DeCS-BVS).

Para a seleção dos artigos, foram pautados os seguintes critérios de inclusão: artigos publicados em periódicos científicos disponíveis na íntegra, com acesso gratuito, e estudos disponíveis em inglês, português ou espanhol. Não fizeram parte deste estudo artigos que não estivessem disponíveis na íntegra, artigos que estivessem repetidos e quaisquer outros documentos que não fossem artigos científicos.

Foi realizado o levantamento de artigos publicados entre 2011 e 2016, o que resultou em 29 artigos. Entre estes, 25 estavam disponíveis na íntegra. Seguindo os critérios de inclusão e exclusão, 10 artigos foram selecionados. Os artigos selecionados são derivados de pesquisas qualitativas. A análise dos artigos permitiu a sistematização em duas categorias: "O trabalho em rede com mulheres em situação de violência" (quadro 2) e "Limites e necessidades profissionais para o enfrentamento da violência de gênero" (quadro 3).

\section{RESULTADOS E DISCUSSŌES}

$\mathrm{Na}$ primeira categoria, denominada " $\mathrm{O}$ trabalho em rede com mulheres em situação de violência", foi montado um quadro com os artigos selecionados (quadro 2), dividido pelos títulos dos artigos, autores, tipo de estudo e ano de publicação. 
Quadro 2 - 0 trabalho em rede com mulheres em situação de violência

\begin{tabular}{|c|c|c|c|}
\hline Título & $\begin{array}{l}\text { Tipo de } \\
\text { estudo }\end{array}$ & Referência & Resultados / Conclusões \\
\hline $\begin{array}{l}\text { A construção } \\
\text { do cuidado: o } \\
\text { atendimento às } \\
\text { situações de violência } \\
\text { doméstica por equipes } \\
\text { de saúde da família. }\end{array}$ & $\begin{array}{l}\text { Estudo } \\
\text { qualitativo. }\end{array}$ & $\begin{array}{l}\text { Moreira, } \\
\text { Martins, } \\
\text { Feuerwerker, } \\
\text { \& Schraiber } \\
\text { (2014). }\end{array}$ & $\begin{array}{l}\text { As estratégias de construção de cuidados } \\
\text { incluíram ações de vinculação à família, } \\
\text { de monitoramento dos casos e avaliação } \\
\text { dos aspectos biomédicos, e também ações } \\
\text { incisivas, como a internação compulsória, } \\
\text { além da construção de um trabalho em } \\
\text { rede. }\end{array}$ \\
\hline $\begin{array}{l}\text { Caring for women } \\
\text { facing domestic } \\
\text { violence: grounded } \\
\text { theory. }\end{array}$ & $\begin{array}{l}\text { Estudo } \\
\text { qualitativo. }\end{array}$ & $\begin{array}{l}\text { Gomes, } \\
\text { Erdmann et al. } \\
\text { (2013). }\end{array}$ & $\begin{array}{l}\text { A gestão da ESF para o cuidado à mulher } \\
\text { deve valorizar a fala das usuárias, a } \\
\text { formação de vínculo, a criação de } \\
\text { espaços de discussão sobre a temática } \\
\text { e a articulação intersetorial e com a } \\
\text { universidade. A Enfermagem é essencial no } \\
\text { processo de gestão e integração no âmbito } \\
\text { da ESF. }\end{array}$ \\
\hline $\begin{array}{l}\text { Enfrentamento da } \\
\text { violência conjugal no } \\
\text { âmbito da estratégia } \\
\text { saúde da família. }\end{array}$ & $\begin{array}{l}\text { Estudo } \\
\text { qualitativo. }\end{array}$ & $\begin{array}{l}\text { Gomes, Bonfim } \\
\text { et al. (2014). }\end{array}$ & $\begin{array}{l}\text { A identificação da violência conjugal como } \\
\text { agravo associado à demanda da mulher no } \\
\text { serviço de saúde, a notificação dos casos } \\
\text { suspeitos ou confirmados, a percepção por } \\
\text { parte dos profissionais da complexidade do } \\
\text { fenômeno e a articulação intersetorial com } \\
\text { outras áreas de atenção, são elementos } \\
\text { que contribuem para o enfrentamento da } \\
\text { problemática. }\end{array}$ \\
\hline $\begin{array}{l}\text { The practice of family } \\
\text { health strategy } \\
\text { workers when caring } \\
\text { for women in gender } \\
\text { violence situations. }\end{array}$ & $\begin{array}{l}\text { Estudo } \\
\text { qualitativo. }\end{array}$ & $\begin{array}{l}\text { Rodrigues et } \\
\text { al. (2014). }\end{array}$ & $\begin{array}{l}\text { Foi ressaltada a necessidade de qualificação } \\
\text { das equipes da Estratégia de Saúde da } \\
\text { Família para atuação nas situações de } \\
\text { violência de gênero, e fomento pela gestão } \\
\text { pública para a estruturação da rede de } \\
\text { serviços assistenciais. }\end{array}$ \\
\hline $\begin{array}{l}\text { Cuidado às mulheres } \\
\text { em situação de } \\
\text { violência conjugal: } \\
\text { importância do } \\
\text { psicólogo na Estratégia } \\
\text { de Saúde da Família. }\end{array}$ & $\begin{array}{l}\text { Estudo } \\
\text { qualitativo. }\end{array}$ & $\begin{array}{l}\text { Gomes, } \\
\text { Erdmann et al. } \\
\text { (2014). }\end{array}$ & $\begin{array}{l}\text { O estudo mostra que as mulheres em } \\
\text { vivência de violência conjugal necessitam } \\
\text { de apoio psicológico e as referenciam para } \\
\text { o psicólogo, por considerá-los mais bem } \\
\text { preparados para o "empoderamento" } \\
\text { da mulher no sentido de romper com a } \\
\text { situação de violência. Todavia, queixam-se } \\
\text { do número limitado de psicólogos. }\end{array}$ \\
\hline $\begin{array}{l}\text { Relações familiares no } \\
\text { contexto da violência } \\
\text { de gênero. }\end{array}$ & $\begin{array}{l}\text { Estudo } \\
\text { qualitativo. }\end{array}$ & $\begin{array}{l}\text { Palmarella, } \\
\text { Diniz, Carvalho, } \\
\text { Menezes, \& } \\
\text { Freire (2016). }\end{array}$ & $\begin{array}{l}\text { Cabe aos profissionais de saúde, mas à } \\
\text { gestão pública estruturar os serviços da } \\
\text { rede de violência de gênero, de maneira a } \\
\text { propiciar à mulher e a seus familiares uma } \\
\text { rede efetiva e intersetorialmente articulada. }\end{array}$ \\
\hline
\end{tabular}

Fonte: elaborado pelos autores. 
Os artigos agrupados na primeira categoria ressaltam que as dificuldades apresentadas pelos profissionais da ESF, para a identificação e enfrentamento dos casos de violência contra a mulher, estão diretamente ligadas a questôes como a criação de vínculos com as famílias, notificação, monitoramento e avaliação dos casos, falta de capacitação específica sobre o fenômeno social da violência contra mulheres, falta de apoio psicológico destinado aos profissionais de saúde e um trabalho em rede intersetorial em que possam ter uma referência e contrarreferência em relação aos casos atendidos.

Muitas vezes, o caminho encontrado pelos familiares para dar apoio à vítima de violência é importante, mas não é suficiente, levando em consideração que, em determinado momento, a situação de violência se torna insustentável, requerendo ajuda institucional dos serviços da rede de atenção à violência (Palmarella, Diniz, Carvalho, Menezes, \& Freire, 2016).

Desde 2006, com a promulgação da Lei Maria da Penha, foi preconizada a criação de ações articuladas com apoio da União, dos Estados, do Distrito Federal, dos Municípios, de espaços não governamentais; a integração entre o Poder Judiciário, o Ministério Público, a Defensoria Pública e as áreas de Segurança Pública, Assistência Social, Saúde, Educação, Trabalho e Habitação.

Em 2008, foram criados pelo Ministério da Saúde os Núcleos de Apoio à Saúde da Família (NASF), com o objetivo de apoiar a consolidação da atenção primária no Brasil, ampliando as ofertas de saúde na rede de serviços, assim como a resolutividade, a abrangência e o alvo das ações. Essa atuação integrada permite realizar discussões de casos clínicos, possibilitando o atendimento compartilhado entre profissionais, tanto na unidade de saúde como nas visitas domiciliares, permitindo, assim, a construção conjunta de projetos terapêuticos, de forma que amplia e qualifica as intervenções no território e na saúde de grupos populacionais. Essas ações de saúde também podem ser intersetoriais, com foco prioritário nas ações de prevenção e promoção da saúde.

Assim, podemos pensar em uma articulação do trabalho em rede para ter um sistema de notificação eficaz, levando em conta a avaliação e monitoramento dos casos de violência, e, com isso, criar um fluxo de referência para o atendimento das vítimas de violência doméstica e intrafamiliar.

A necessidade de criação e de fortalecimento da rede de atendimento para as mulheres em situação de violência leva em conta a necessidade de evitar que essas mulheres tenham de percorrer o que Sagot (2007) nomeou como "rota crítica". A autora considera que, após a tomada de decisão das mulheres que sofrem violência, pela denúncia e pela demanda de proteção e amparo, elas se veem, 
muitas vezes, obrigadas a percorrer diversos equipamentos públicos policiais, jurídicos, de Assistência Social e de Saúde, nos quais são impelidas a repetir sua história e providenciar, elas mesmas, o encaminhamento de seu "processo". Esse processo é "crítico", pois pode induzir a mulher a desistir de sua demanda ou a fazê-la percorrer um longo caminho, que demanda um grande tempo, ocupado em idas e vindas.

A "rota crítica" percorrida pelas mulheres é um acontecimento que impele a ocorrência de novos episódios de violência. Em casos extremos, pode levar à morte das mulheres. A análise da "rota crítica" mostra a falta de conexão entre os diversos pontos da rede de proteção às mulheres e de enfrentamento da violência, bem como a necessidade de fortalecimento da rede.

A situação de violência exige que os profissionais de saúde busquem a construção de estratégias que lhes permitam maior conexão com os equipamentos de assistência social, policiais e jurídicos voltados para a atenção às mulheres em situação de violência, bem como para a escuta qualificada da história de vida das mulheres que sofrem agravos de saúde em decorrência da violência de gênero.

Diante da contextualização do fenômeno atual da violência doméstica na atenção primária encontrada pelos profissionais de saúde, percebe-se que o problema está além da capacitação dos profissionais e da criação de políticas públicas, pois é necessário que haja maior conectividade nas ações intersetoriais no âmbito da saúde (Schwantes, Chiesa, Berti, \& Fracolli, 2011).

É necessário que os profissionais de saúde busquem compreender a inserção e os vínculos familiares e sociais das mulheres agredidas, as vulnerabilidades e os aspectos protetivos presentes nas redes comunitárias, sociais e familiares de cada uma dessas mulheres. A atenção primária organizada a partir da ESF oferece condiçôes favoráveis para a construção de práticas voltadas ao enfrentamento da violência doméstica e para a potencialização dos recursos subjetivos das mulheres para a superação da violência doméstica e intrafamiliar (Moreira, Martins, Feuerwerker, \& Schraiber, 2014).

Entre os profissionais que poderiam melhorar a atenção às mulheres vítimas dos agravos de saúde decorrentes da vivência, podemos destacar os psicólogos das unidades de saúde, por serem profissionais cuja formação promove habilidades e competências para a realização da escuta qualificada e prestar o apoio psicológico necessário para o enfrentamento da violência conjugal, que contribui para que as mulheres possam elaborar suas vivências e construir alternativas para a promoção de sua autonomia (Gomes et al., 2013). 
$\mathrm{Na}$ segunda categoria, denominada "Limites e necessidades profissionais para o enfrentamento da violência de gênero", foram agrupados os artigos descritos, conforme o quadro 3, a seguir.

Quadro 3 - Limites e necessidades profissionais para o enfrentamento da violência de gênero

\begin{tabular}{|c|c|c|c|}
\hline Título & $\begin{array}{l}\text { Tipo de } \\
\text { estudo }\end{array}$ & Referência & Resultados/Conclusões \\
\hline $\begin{array}{l}\text { Limites e possibilidades } \\
\text { avaliativas da estratégia } \\
\text { saúde da família para a } \\
\text { violência de gênero. }\end{array}$ & $\begin{array}{l}\text { Estudo } \\
\text { qualitativo. }\end{array}$ & $\begin{array}{l}\text { Guedes, } \\
\text { Fonseca, \& Egry } \\
\text { (2013). }\end{array}$ & $\begin{array}{l}\text { Foram constatadas possibilidades } \\
\text { relacionadas ao vínculo propiciado } \\
\text { pela lógica de atenção instaurada } \\
\text { com a ESF, ainda que cerceadas } \\
\text { pelas limitações do modelo } \\
\text { biomédico e a ausência de } \\
\text { tecnologias específicas para lidar } \\
\text { com a violência. }\end{array}$ \\
\hline $\begin{array}{l}\text { Health needs: the } \\
\text { interface between the } \\
\text { discourse of health } \\
\text { professionals and } \\
\text { victimized women. }\end{array}$ & $\begin{array}{l}\text { Estudo } \\
\text { qualitativo. }\end{array}$ & $\begin{array}{l}\text { Oliveira \& } \\
\text { Fonseca (2015). }\end{array}$ & $\begin{array}{l}\text { Os discursos de mulheres usuárias e } \\
\text { de profissionais de saúde revelaram } \\
\text { necessidades propriamente } \\
\text { humanas, a exemplo da autonomia } \\
\text { e do vínculo, além da limitação } \\
\text { ao reconhecimento dos casos de } \\
\text { violência e dificuldades para o } \\
\text { enfrentamento das necessidades em } \\
\text { saúde das mulheres. }\end{array}$ \\
\hline $\begin{array}{l}\text { A autonomia } \\
\text { como necessidade } \\
\text { estruturante para o } \\
\text { enfrentamento da } \\
\text { violência de gênero. }\end{array}$ & $\begin{array}{l}\text { Estudo } \\
\text { qualitativo. }\end{array}$ & $\begin{array}{l}\text { Guedes \& } \\
\text { Fonseca (2011). }\end{array}$ & $\begin{array}{l}\text { O enfrentamento da violência } \\
\text { é fundamental a inclusão da } \\
\text { perspectiva de gênero tanto nas } \\
\text { políticas de saúde quanto nas } \\
\text { práticas concretizadas no processo } \\
\text { de trabalho, condição que abre } \\
\text { possibilidades de repostas a } \\
\text { necessidades práticas e estratégicas } \\
\text { de gênero, contribuindo para } \\
\text { a redução da iniquidade entre } \\
\text { homens e mulheres e a promoção } \\
\text { da emancipação feminina. }\end{array}$ \\
\hline $\begin{array}{l}\text { Violência contra } \\
\text { as mulheres na } \\
\text { perspectiva dos agentes } \\
\text { comunitários de saúde. }\end{array}$ & $\begin{array}{l}\text { Estudo } \\
\text { qualitativo. }\end{array}$ & $\begin{array}{l}\text { Hesler et al. } \\
\text { (2013). }\end{array}$ & $\begin{array}{l}\text { Em relação às práticas de cuidado } \\
\text { e enfrentamento, observaram-se } \\
\text { algumas ferramentas: a construção } \\
\text { de estratégias de cuidado junto com } \\
\text { a equipe; vínculo, escuta e diálogo } \\
\text { com a mulher vítima de violência. }\end{array}$ \\
\hline
\end{tabular}




\begin{tabular}{|c|c|c|c|}
\hline $\begin{array}{l}\text { Significado da } \\
\text { capacitação profissional } \\
\text { para o cuidado da } \\
\text { mulher vítima de } \\
\text { violência conjugal. }\end{array}$ & $\begin{array}{l}\text { Estudo } \\
\text { qualitativo. }\end{array}$ & $\begin{array}{l}\text { Gomes, } \\
\text { Erdmann, } \\
\text { Bettinelli et al. } \\
\text { (2013). }\end{array}$ & $\begin{array}{l}\text { A dificuldade de reconhecer } \\
\text { o agravo à mulher e os } \\
\text { encaminhamentos ao sistema } \\
\text { de referência e contrarreferência } \\
\text { constituem os principais desafios } \\
\text { para o enfrentamento da } \\
\text { problemática. Os profissionais } \\
\text { propõem a capacitação enquanto } \\
\text { estratégica para garantia do } \\
\text { cuidado. }\end{array}$ \\
\hline $\begin{array}{l}\text { Domestic violence } \\
\text { against women: social } \\
\text { representation of the } \\
\text { health community } \\
\text { agents. }\end{array}$ & $\begin{array}{l}\text { Estudo } \\
\text { qualitativo. }\end{array}$ & $\begin{array}{l}\text { Broch et al. } \\
\text { (2016). }\end{array}$ & $\begin{array}{l}\text { Trata-se de uma representação } \\
\text { fundamentada em aspectos } \\
\text { negativos e estruturada por } \\
\text { conter as dimensões: conceito, } \\
\text { atitude e imagem, espera-se um } \\
\text { trabalho articulado na prevenção, } \\
\text { identificação e ampliação de } \\
\text { estratégias para o enfrentamento } \\
\text { da violência doméstica. }\end{array}$ \\
\hline $\begin{array}{l}\text { Violência contra a } \\
\text { mulher na perspectiva } \\
\text { de agentes comunitários } \\
\text { de saúde. Estudo } \\
\text { qualitativo. }\end{array}$ & $\begin{array}{l}\text { Estudo } \\
\text { qualitativo. }\end{array}$ & $\begin{array}{l}\text { Lima \& Pacheco } \\
\text { (2016). }\end{array}$ & $\begin{array}{l}\text { Evidenciou-se a necessidade } \\
\text { de orientações relativas à } \\
\text { conceituação, identificação dos } \\
\text { casos e formas de intervenção, } \\
\text { permitindo que os profissionais } \\
\text { atuem com mais segurança. }\end{array}$ \\
\hline
\end{tabular}

Fonte: elaborado pelos autores.

Em comum, nas descrições e análises apresentadas nos artigos agrupados nesta segunda categoria, ressaltam-se as principais limitações e necessidades dos profissionais que atuam nas equipes de saúde da família, e que estão relacionadas ao vínculo propiciado pela lógica de atenção instaurada com a ESF, ainda que cerceadas pelas limitações do modelo biomédico e a ausência de tecnologias específicas para lidar com a violência (Guedes, Fonseca, \& Egry, 2013).

Se, de um lado, a lógica da ESF possibilita maior aproximação entre os profissionais de saúde os usuários e usuárias dos serviços de saúde daquele território; de outro ainda permanecem as relaçôes hierarquizadas entre os profissionais de saúde e clientes. Especificamente em relação à vivência da violência, há a dificuldade das mulheres, que, por medo, vergonha, silenciam-se e relatam aos profissionais os atos de violência física, sexual ou psicológica que sofreram. Por outro, os profissionais de saúde não indagam às mulheres sobre a vivência de violência, quer por temerem envolver-se emocionalmente com as histórias e dramas vividos pelas mulheres, quer por temerem alguma retaliação por parte dos agressores. Em síntese, os profissionais não perguntam, e as mulheres não falam, denunciando a dificuldade da comunicação, e o silêncio e a invisibilidade da violência em consequência de sentimentos de medo, vergonha e preconceito (Lima \& Pacheco, 2016). 
Outro fator dificultador para que as mulheres e os profissionais se sintam à vontade para conversarem livremente sobre os episódios de violência conjugal e doméstica por parte de suas clientes está associado, em alguns casos, à falta de espaço para um atendimento mais reservado e que permita a preservação do sigilo do relato (Schraiber et al., 2003).

Tratar dos agravos à saúde causados pela violência doméstica e intrafamiliar não tem sido fácil para os profissionais de saúde. Percebemos que há lacunas na formação profissional para o diagnóstico e enfrentamento da violência. Além disso, os profissionais de saúde ressentem-se da falta de apoio psicossocial que os ajude a elaborar as vivências cotidianas, bem como de apoio institucional para que possam cumprir a exigência da notificação compulsória.

Como sabemos, foi instituído pelo Ministério da Saúde, com vistas à construção de uma epidemiologia da violência, a ficha de notificação compulsória a ser preenchida e encaminhada pelos profissionais que atendem pessoas vítimas de violência as quais apresentam danos físicos e psicológicos.

No entanto, embora os profissionais tenham ciência dessa exigência, é comum que não a cumpram, pois revelam certo receio quanto às consequências policiais e judiciais da notificação. Além disso, temem serem retaliados pelos autores da violência, uma vez que esses homens são também moradores do território e usuários dos serviços de saúde.

A ausência de protocolos específicos e o desconhecimento da existência de uma rede estruturada de atendimento às mulheres vítimas de violência por parte dos profissionais da ESF, em alguns contextos, podem contribuir para a incapacidade de abordar a questão em sua prática assistencial (Lima \& Pacheco, 2016).

O enfrentamento da violência contra a mulher compreende as dimensões da prevenção, da assistência e da garantia de direitos das mulheres. Essas dimensões compõem os eixos estruturantes da Política Nacional de Enfrentamento à Violência contra as Mulheres. Os eixos são voltados para a prevenção, com a criação de ações educativas que eliminem os padrões relacionais sexistas e promovam uma equidade de gênero; assistência, com o fortalecimento da rede de atendimento e capacitação de agentes públicos; enfrentamento e combate, que estão associados a ações punitivas e ao cumprimento da Lei Maria da Penha; e acesso e garantia de direitos, em respeito aos tratados internacionais de direitos humanos e a promoção de iniciativas para a autonomia das mulheres (Ministério da Saúde, 2011). 
Em seus estudos, Guedes e Fonseca (2011) e Oliveira e Fonseca (2015) mostraram que a limitação do reconhecimento dos casos de violência vividos pelas mulheres, por parte dos profissionais de saúde, demonstra a necessidade da capacitação continuada que ofereça ferramentas teórico-metodológicas para o enfrentamento das necessidades em saúde das mulheres em condição de violência. Neste, consideram como fundamental a inclusão da perspectiva de gênero tanto nas políticas de saúde quanto nas práticas cotidianas, no processo de trabalho das ESF.

As dificuldades de reconhecer os agravos à saúde da mulher causados pela violência e o domínio de informações sobre a rede de assistência para a realização de encaminhamentos ao sistema de referência e contrarreferência constituem os principais desafios para o enfrentamento da problemática. Em relação às práticas de cuidado e enfrentamento, observaram-se algumas ferramentas: a construção de estratégias de cuidado junto com a equipe, vínculo, escuta e diálogo com a mulher vítima de violência.

Segundo a Secretaria de Atenção à Saúde do Departamento de Atenção Básica do Ministério da Saúde, as secretarias estaduais e municipais devem desenvolver ações e articular instituições para formação e garantia de educação permanente aos profissionais de saúde das equipes de atenção básica e das equipes de Saúde da Família. Assim, os municípios podem receber um recurso complementar relacionado ao enfrentamento de especificidades geradoras de iniquidade (Ministério da Saúde, 2008, 2012).

Os municípios que têm os NASF na atenção primária da saúde têm como particularidade a realização de ações que visam à saúde da mulher. Essas ações podem contribuir para o enfrentamento da violência contra mulheres, minimizando as limitações e necessidades apontadas pelos profissionais ligados à rede de saúde. Em síntese, os objetivos expostos pela (Portaria no 154/2008) são:

a) apoiar a ESF na abordagem e no processo de trabalho referente aos casos de agravos severos e, ou, persistentes de saúde da mulher, além de situações específicas, como a de violência intrafamiliar;

b) realizar, junto com a ESF, o planejamento das ações de saúde da mulher;

c) priorizar as abordagens coletivas, identificando os grupos estratégicos para que a atenção em saúde da mulher se desenvolva nas unidades de saúde e em outros espaços na comunidade; 
d) ampliar o vínculo com as famílias, tomando-as como parceiras no tratamento e buscando constituir redes de apoio e integração;

e) realizar visita domiciliar em conjunto com as equipes de saúde da família com base em necessidades identificadas;

f) criar, em conjunto com as equipes, estratégias para abordar problemas que se traduzam em maior vulnerabilidade;

g) evitar práticas que levem à medicalização de situaçôes individuais e sociais, comuns à vida cotidiana.

A Política Nacional de Enfrentamento à Violência Contra Mulheres reforça a necessidade de ações de prevenção, combate e assistência às mulheres em situação de violência, considerando a ESF como lócus privilegiado de intervenção. Essa política vem sendo implantada desde 1994 como um modelo de atenção na reorganização da atenção básica de saúde no País (Ministério da Saúde, 2011).

O enfrentamento do complexo problema da violência doméstica e intrafamiliar requer políticas e ações coordenadas intersetorialmente, com a participação tanto do Estado quanto da sociedade civil, como revelam as pesquisas realizadas com os profissionais de saúde.

\section{CONSIDERAÇŌES FINAIS}

Os profissionais que atuam na ESF apontaram as limitações que encontram, em seu trabalho cotidiano com as mulheres que vivem situaçôes de violência contínuas, que provocam danos à saúde. Eles entendem que, para o enfrentamento da violência doméstica e intrafamiliar cometida contra as mulheres, é necessário que se promova maior e mais eficaz articulação entre as equipes e a rede de atendimento.

A complexidade da articulação entre os setores de referência e contrarreferência constitui elemento que contribui para o enfrentamento do fenômeno. Esse processo requer comprometimento e reorganização política local, a partir de uma gestão que valorize a violência contra as mulheres como um problema de saúde pública.

A formação profissional continuada é fundamental para que haja uma melhor percepção sobre os agravos à saúde da mulher no que tange a identificação e acompanhamento dos casos. 
É importante trabalhar com a capacitação profissional, no sentido de sensibilizar os profissionais para que percebam, na história das mulheres, a vivência da violência. Nem sempre a queixa da violência sofrida será explícita, muitas vezes são feitos relatos que tentam encobrir a causa de um ferimento ou dos sintomas depressivos. O sentimento da vergonha pela violência sofrida nas relações conjugais e afetivas, muitas vezes, silencia as mulheres.

É preciso que os profissionais de saúde estejam bem formados e amparados subjetivamente para que não façam aliança com o silêncio e com as tentativas de encobrimento da realidade feitas pelas mulheres. É preciso que os profissionais de saúde não se tornem cúmplices da violência. Nesse sentido, é de extrema importância a inclusão, na pauta da formação continuada, das reflexões sobre as desigualdades de gênero e sobre a naturalização da violência contra as mulheres. 


\section{REFERÊNCIAS}

Azevedo, M. A. \& Guerra, V. N. A. (2007). Crianças vitimizadas: a sindrome do pequeno poder. (2a ed.). São Paulo: Iglu.

Brasil. (2015). Violência doméstica e familiar contra a mulher. Brasília: DataSenado.

Brito, C. D. (2015). No embalo da rede: conexōes e desconexóes no enfrentamento da violência contra as mulheres em Belo Horizonte. Curitiba: CRV.

Brito, D. (2018, 7 agosto). Denúncias de violência contra a mulher chegam a 73 mil, em 2018: Lei Maria da Penha completa 12 anos em meio a notícias de feminicídio. Agência Brasil, Brasília. Recuperado a partir de https:// agenciabrasil.ebc.com.br/direitos-humanos/noticia/2018-08/denuncias-deviolencia-contra-mulher-chegam-73-mil-em-2018

Broch, D., Gomes, V. L. O., Silva, C. D., Gomes, G. C., Abreu, D. P. G., \& Mattos, M. B. (2016, October). Domestic violence against women: social representation of the health community agent. Journal of Nursing UFPE, 10(10), 3543-3550.

Centro Latino-Americano e do Caribe de Informação em Ciências da Saúde, Organização Pan-Americana de Saúde, Organização Mundial de Saúde. (s.d.). Biblioteca virtual em saúde Brasil. Brasília: OPAS.

Ganong L. H. (1987). Integrative reviews of nursing research. Research in Nursing \& Health, 10(1), 1-11.

Gomes, N. P., Bonfim, A. N. A., Barros, R. D., Silva Filho, C. C., \& Diniz, N. M. F. (2014). Enfrentamento da violência conjugal no âmbito da estratégia saúde da família. Revista Enfermagem UERJ, 22(4), 477-481.

Gomes, N. P., Erdmann, A. L., Bettinelli, L. A., Higashi, G. D. C., Carneiro, J. B., \& Diniz, N. M. F. (2013). Significado da capacitação profissional para o cuidado da mulher vítima de violência conjugal. Escola Anna Nery, 17(4), 683-689.

Gomes, N. P., Erdmann, A. L., Santos, J. L. G., Mota, R. S., Lira, M. O. S. C., \& Meirelles, B. H. S. (2013) Caring for women facing domestic violence: Grounded Theory. Brazilian Journal of Nursing, 12(4), 782-93.

Gomes, N. P., Erdmann, A. L., Stulp, K. P., Diniz, N. M. F., Correia, C. M., \& Andrade, S. R. (2014). Cuidado às mulheres em situação de violência conjugal: 
importância do psicólogo na Estratégia de Saúde da Família. Psicologia USP, 25(1), 63-69.

Guedes, R. N., \& Fonseca, R. M. G. S. (2011). A autonomia como necessidade estruturante para o enfrentamento da violência de gênero. Revista da Escola de Enfermagem da USP, 45(2), 1731-1735.

Guedes, R. N., Fonseca, R. M. G. S., \& Egry, E. Y. (2013). Limites e possibilidades avaliativas da estratégia saúde da família para a violência de gênero. Revista da Escola de Enfermagem da USP, 47(2), 304-311.

Hesler, L. Z., Costa, M. C., Resta, D. G., \& Colomé, I. C. S. (2013). Violência contra as mulheres na perspectiva dos agentes comunitários de saúde. Revista Gaúcha de Enfermagem, 34(1), 180-186.

Lei no 11.340, de 7 de agosto de 2006. (2006, 7 agosto). Cria mecanismos para coibir a violência doméstica e familiar contra a mulher, nos termos do $₫ 8^{\circ}$ do art. 226 da Constituição Federal, da Convenção sobre a Eliminação de Todas as Formas de Discriminação contra as Mulheres e da Convenção Interamericana para Prevenir, Punir e Erradicar a Violência contra a Mulher; dispõe sobre a criação dos Juizados de Violência Doméstica e Familiar contra a Mulher; altera o Código de Processo Penal, o Código Penal e a Lei de Execução Penal; e dá outras providências. (Lei Maria da Penha). Diário Oficial União, Brasília. Recuperado a partir de http://www.planalto.gov.br/ccivil_03/_ato20042006/2006/lei/l11340.htm

Lima, N. J. S. O., \& Pacheco, L. R. (2016). Violência doméstica contra a mulher na perspectiva de agentes comunitários de saúde. Revista de Enfermagem da UFPE, 10(5), 4279-4285.

Mendes, K. D. S., Silveira, R. C. C. P., \& Galvão, C. M. (2008). Revisão integrativa: método de pesquisa para a incorporação de evidências na saúde e na enfermagem. Revista Gaúcha de Enfermagem, 17(4), 758-764.

Ministério da Saúde. (2008). Secretaria de Atenção à Saúde. Departamento de Atenção Básica. Saúde da Família no Brasil: uma análise de indicadores selecionados: 1998-2005/2006. (2a ed.). Brasília: Ministério da Saúde.

Ministério da Saúde. (2011). Secretaria de Políticas para as Mulheres. Política Nacional de Enfrentamento à Violência contra as Mulheres. Brasília: Ministério da Saúde. 
Ministério da Saúde. (2012). Secretaria de Atenção à Saúde. Departamento de Atenção Básica. Política Nacional de Atenção Básica. Brasília: Ministério da Saúde.

Moreira, M. I. C., \& Sousa, S. M. G. (2013). Quebrando o silêncio: Disque 100 - Estudo sobre a denúncia de violência sexual contra crianças e adolescentes no Brasil. Goiânia: Cânone.

Moreira, T. N. F., Martins, C. L., Feuerwerker, L. C. M., \& Schraiber, L. B. (2014). A construção do cuidado: o atendimento às situações de violência doméstica por equipes de Saúde da Família. Saúde e Sociedade, 23(3), 814-827.

Oliveira, R. N. G., \& Fonseca, R. M. G. S. (2015). Health needs: the interface between the discourse of health professionals and victimized women. Revista Latino-americana de Enfermagem, 23(2), 299-306.

Palmarella, R. V., Diniz, R. A., Carvalho, L. M. O. S., Menezes, C. T., \& Freire, D. N. M. (2016). Relações familiares no contexto da violência de gênero. Contexto Enfermagem, 25(3), e2530015.

Pan American Health Organization. (2013). Centers for Disease Control and Prevention (CDC). Summary report: violence against women in Latin America and the Caribbean: a comparative analysis of population-based data from 12 countries. Washington: PAHO.

Pompeo, D. A., Rossi, L. A., \& Galvão, C. M. (2009). Revisão integrativa: etapa inicial do processo de validação de diagnóstico de enfermagem. Acta Paulista de Enfermagem, 22(4), 434-438.

Portaria no 154, de 24 de janeiro de 2008. (2008, 24 janeiro). Cria os Núcleos de Apoio à Saúde da Família - NASF. Diário Oficial da União, Brasília.

Rodrigues, V. P., Machado, J. C., Simões, A. V., Pires, V. M. M. M., Paiva, M. S., \& Diniz, N. M. F. (2014). The practice of family health strategy workers when caring for women in gender violence situations. Texto \& Contexto Enfermagem, $23(3), 735-743$.

Saffioti, H., \& Almeida, S. S. (1995). Violência de gênero: poder e impotência. Rio de Janeiro: Revinter.

Sagot, M. (2007). Rotas criticas: mulheres enfrentando violência: a rota crítica da violência intrafamiliar em paises latino-americanos. São Leopoldo: Editora Unisinos. 
Schraiber, L., d'Oliveira, A. F., Hanada, H., Figueiredo, W., Couto, M., Kiss, L., . . \& Pinho, A. (2003). Violência vivida: a dor que não tem nome. Interface, $7(12), 41-54$.

Schwantes, L. C., Chiesa, A. M., Berti, R. A. L., \& Fracolli, L. A. (2011, outubrodezembro). Violência doméstica: analisando a visão do profissional de saúde na atenção primária. HU Revista, 37(4), 449-456.

Scott, J. (1995). Gênero: uma categoria útil de análise histórica. Educação e Realidade, 20(2), 71-99.

Sousa, S. M. G., \& Moreira, M. I. C. (2012). Atendimento psicossocial de crianças $e$ adolescentes em situação de abuso sexual. Goiânia: Cânone. 